\title{
Southern Ocean Response to Relative Velocity Wind Stress Forcing
}

\author{
David K. Hutchinson And ANDREw McC. HogG \\ The Australian National University, Canberra, Australian Capital Territory, Australia \\ JEFFREY R. BLUNDELL \\ National Oceanography Centre, Southampton, Southampton, United Kingdom
}

(Manuscript received 12 February 2009, in final form 1 September 2009)

\begin{abstract}
An eddy-resolving quasigeostrophic model of the Southern Ocean coupled to a dynamic atmospheric mixed layer is used to compare the performance of two different wind stress parameterization schemes. The first is the standard quadratic drag law, based on atmospheric velocity alone, whereas the second (more exact) formulation is based on the difference between ocean and atmosphere velocities. The two different schemes give very similar magnitudes of mean stress; however, the relative velocity scheme has substantially lower power input, resulting in a weaker eddy field, and consequently, greater circumpolar transport. These results are explored in terms of the existing theories of the Antarctic Circumpolar Current (including eddy saturation and eddy damping) and the implications for modeling the Southern Ocean are discussed.
\end{abstract}

\section{Introduction}

Scatterometer observations of wind stress at the ocean's surface show clear evidence of both large-scale atmospheric features and smaller-scale features resulting from interactions with the ocean (Chelton et al. 2004). The small-scale oceanic features are caused by two primary mechanisms. The first mechanism is that of the ocean velocity, since stress can be approximated as a quadratic function of the relative velocity between the atmosphere and ocean (Pacanowski 1987). The second mechanism is the influence of sea surface temperature (SST). Small-scale stress gradients have been shown to correlate strongly with SST gradients (O'Neill et al. 2003; Nonaka and Xie 2003; Chelton et al. 2004), demonstrating that a coupling mechanism exists between SST and stress.

The signature of ocean currents in scatterometer measurements of stress has been demonstrated by a comparison of scatterometer stress fields with buoy measurements (Kelly et al. 2001). Scatterometers estimate stress directly, explicitly accounting for the relative

Corresponding author address: Andrew McC. Hogg, Research School of Earth Sciences, The Australian National University, Canberra, ACT 0200, Australia.

E-mail: andy.hogg@anu.edu.au velocity between the wind and ocean, whereas the buoy measurements infer stress from the wind velocity alone. Ocean currents have also been inferred directly from scatterometer observations using high-pass spatial filtering (Cornillon and Park 2001; Park et al. 2006) because ocean velocities vary on smaller-length scales more than wind velocities. It is widely acknowledged that wind stress has some dependence on ocean velocity; however, the influence of this dependence upon basin-scale flow has only recently been investigated (Duhaut and Straub 2006; Dawe and Thompson 2006; Zhai and Greatbatch 2007). This paper focuses on the ocean velocity contribution to the stress, by examining its impact on a channel model of the Antarctic Circumpolar Current (ACC).

\section{a. Relative velocity stress parameterization}

Wind stress $\tau$ can be parameterized by a simple quadratic function of the difference between atmospheric velocity at $10-\mathrm{m}$ altitude $\mathbf{u}_{a}$ and the ocean surface velocity $\mathbf{u}_{o}$ (Pacanowski 1987),

$$
\boldsymbol{\tau}_{1}=\rho_{a} C_{d}\left|\mathbf{u}_{a}-\mathbf{u}_{o}\right|\left(\mathbf{u}_{a}-\mathbf{u}_{o}\right),
$$

where $\rho_{a}$ is the density of air at sea level and $C_{d}$ is the drag coefficient, which is approximated as a constant. Typical atmospheric velocities are of order $\mathbf{u}_{a} \sim 10 \mathrm{~m} \mathrm{~s}^{-1}$, whereas ocean velocities on a basin scale are $\mathbf{u}_{o} \sim 0.2 \mathrm{~m} \mathrm{~s}^{-1}$. 
Thus, Eq. (1) can be approximated by setting $\mathbf{u}_{a}-\mathbf{u}_{o} \approx$ $\mathbf{u}_{a}$, giving a wind stress that depends only on the atmospheric velocity (Pedlosky 1987),

$$
\boldsymbol{\tau}_{0}=\rho_{a} C_{d}\left|\mathbf{u}_{a}\right| \mathbf{u}_{a} .
$$

In some regions, this approximation becomes far less accurate because ocean surface velocities become comparable with wind velocities. Pacanowski (1987) pointed out that in equatorial regions, $\left|\mathbf{u}_{o}\right| \sim 1 \mathrm{~m} \mathrm{~s}^{-1}$ and $\left|\mathbf{u}_{a}\right| \sim$ $6 \mathrm{~m} \mathrm{~s}^{-1}$, so that the use of $\tau_{0}$ introduces errors in $\tau$ of up to $30 \%$. However, in most parts of the ocean, including the Southern Ocean, wind speed is at least an order of magnitude larger than the ocean currents, thus the inclusion of $\mathbf{u}_{o}$ in the wind stress parameterization is a second-order effect. On the other hand, recent studies (Duhaut and Straub 2006; Zhai and Greatbatch 2007) have shown that the power input to the ocean from wind stress is a strong function of this parameterization.

Power input (per unit area) from the wind to the ocean is given by the dot product of the upper-ocean geostrophic velocity and the wind stress (Stern 1975, p. 114). Using the two different parameterizations of wind stress given by Eqs. (1) and (2), we may define the corresponding power inputs $P_{1}$ and $P_{0}$ as

$$
\begin{aligned}
& P_{1}=\mathbf{u}_{o} \cdot \boldsymbol{\tau}_{1} \text { and } \\
& P_{0}=\mathbf{u}_{o} \cdot \boldsymbol{\tau}_{0} .
\end{aligned}
$$

The difference in both stress and power input between the two schemes can be written as

$$
\begin{gathered}
\tau_{\text {diff }}=\tau_{0}-\tau_{1} \text { and } \\
P_{\text {diff }}=P_{0}-P_{1} .
\end{gathered}
$$

Note that $\boldsymbol{\tau}_{\text {diff }}$ is defined so that its sign reflects the error associated with using the simplified atmosphere-only form.

Duhaut and Straub (2006) used a scaling argument to show that including $\mathbf{u}_{o}$ in the wind stress reduces the basin-integrated power input by at least $20 \%$. This occurs despite only a small change in the magnitude of stress. The power reduction is caused by strong correlations between the stress difference $\tau_{\text {diff }}$ and the mesoscale ocean velocity. Duhaut and Straub showed that the difference in stress $\boldsymbol{\tau}_{\text {diff }}$ aligns strongly with the ocean velocity,

$$
\boldsymbol{\tau}_{\text {diff }} \approx \rho_{a} C_{d}\left[\left|\mathbf{u}_{a}\right| \mathbf{u}_{o}+\left(\mathbf{u}_{o} \cdot \hat{\mathbf{u}}_{a}\right) \mathbf{u}_{a}\right],
$$

where the hat denotes a unit vector (note that this estimate of $\boldsymbol{\tau}_{\text {diff }}$ assumes that $\mathbf{u}_{o}$ is independent of the stress parameterization, whereas the results presented below indicate that the wind stress scheme strongly influences ocean velocity in the ACC case). Equation (7) implies that the difference in power scales as the square of the ocean velocity, thus

$$
P_{\mathrm{diff}} \approx \rho_{a} C_{d}\left|\mathbf{u}_{a}\right|\left[\left|\mathbf{u}_{o}\right|^{2}+\left(\mathbf{u}_{o} \cdot \hat{\mathbf{u}}_{a}\right)^{2}\right] .
$$

Duhaut and Straub (2006) investigated this power difference in a quasigeostrophic (QG) model of an idealized double-gyre circulation. They estimated that the basinintegrated power difference, $\left\langle P_{\text {diff }}\right\rangle /\left\langle P_{0}\right\rangle$, had a lower limit of 0.2 based on a scaling argument, and a value of 0.35 based on their QG simulations. Subsequent modeling of the North Pacific (Dawe and Thompson 2006) and the North Atlantic (Zhai and Greatbatch 2007) has found similar values of $\left\langle P_{\text {diff }}\right\rangle /\left\langle P_{0}\right\rangle$. These estimates of the reduction in power have also been supported by scatterometer studies (Hughes and Wilson 2008; Xu and Scott 2008).

Numerical modeling of the impact of using the relative velocity stress parameterization has so far been focused on midlatitude ocean gyres. The present work extends these results to a model of the Southern Ocean, where the circulation is limited by different mechanisms than in gyres. We aim to confirm the Southern Ocean power reduction estimated from scatterometer studies (Hughes and Wilson 2008; $\mathrm{Xu}$ and Scott 2008) and to examine the impacts of the relative velocity stress on the mean flow of the ACC.

The alignment of $\tau_{\text {diff }}$ with the ocean velocity means that the flow is generally damped in regions of high velocity. For example, consider a circularly symmetric eddy flowing clockwise under a uniform westerly wind stress. Under the standard stress, the positive contributions to stress on the northern half of the eddy would be equal in magnitude to the negative contributions on the southern half. However, under the relative velocity stress, the wind stress magnitude would be smaller on the northern half of the eddy and greater on the southern half. Thus, the relative velocity stress parameterization increases the stress in the opposite direction to the flow (Duhaut and Straub 2006; Zhai and Greatbatch 2007; Xu and Scott 2008), acting to damp the eddies. This is analogous to the "top drag" effect found by Dewar and Flierl (1987) in numerical simulations of mesoscale eddies, where oceanic motions decayed more rapidly under the relative velocity stress scheme. We propose that this damping over eddies and jets has the potential to influence the circumpolar transport because eddies are crucial in setting the momentum balance of the ACC. 


\section{b. Dynamics of the ACC}

The lack of zonal boundaries and the high wind stress in the Southern Ocean give rise to a unique circulation: the ACC. The mechanisms that control the circumpolar transport of the ACC continue to be debated, and we briefly review some contending theories here.

Early attempts to model the ACC could not explain the observed circumpolar transport, using realistic constraints of both wind stress and friction (e.g., Hidaka and Tsuchiya 1953; Gill 1968). In light of the discrepancy between friction-based models and observations, Munk and Palmén (1951) proposed that the ACC transport is limited not by friction but by topographic form stress. Because the actual measurement of topographic form stress is not feasible, models have provided the only method of testing Munk and Palmén's hypothesis. However, coarse-resolution models of the ACC, where the grid length is larger than the eddy radius, did not support Munk and Palmén's hypothesis (Gill and Bryan 1971; Bryan and Cox 1972) because for any realistic value of vertical viscosity the downward momentum flux is too small to balance the input of momentum from the wind stress.

Straub (1993) argued that in the presence of eddies the baroclinic transport of the ACC may actually be independent of wind stress (provided that the stress is at least large enough to create baroclinic instability). Using a two-layer QG model of the ACC, Straub argued that the velocity of the flow is approximately limited to the velocity at which baroclinic instability first develops. Eddies create interfacial form stress, which acts to transfer momentum downward much faster than viscous shear forces and enables bottom form stress to act as an effective sink of momentum. This theory is often referred to as eddy saturation. However, the eddy saturation theory assumes that baroclinic instability is dominant throughout the channel, whereas it may only be confined to regions of elevated topography (Hallberg and Gnanadesikan 2001). Under eddy saturation, the predicted baroclinic transport is highly dependent on the stratification (Straub 1993; Hallberg and Gnanadesikan 2001; Hogg and Blundell 2006).

Present day coarse-resolution models use vastly improved eddy parameterization schemes, which allow for an effective vertical momentum flux (see Gent et al. 1995). Thus, realistic values of circumpolar transport in the ACC are now achieved by coarse-resolution models (Gent et al. 2001; Fyfe and Saenko 2005). However, the response of the ACC models to changes in wind forcing depends greatly on the resolution of the model. In coarse-resolution models, circumpolar transport strongly increases with wind stress (Gent et al. 2001; Fyfe and
Saenko 2005), whereas eddy-resolving models show little or no change in circumpolar transport when wind stress is increased (Hallberg and Gnanadesikan 2006; Meredith and Hogg 2006; Hogg and Blundell 2006). Instead, the increased momentum input from the wind creates a more vigorous eddy field. Recent observational studies of the ACC have found that the tilt of the isopycnal surfaces across the ACC has remained approximately constant over the past few decades (Böning et al. 2008; Gille 2008). The constant isopycnal tilt implies that the geostrophic circumpolar transport relative to the bottom has remained constant, despite an increase in westerly winds over the same period. The observations of Böning et al. (2008) and Gille (2008) provide evidence for the eddy saturation theory (Straub 1993) and support the findings of eddy-resolving channel models of the ACC.

Diapycnal overturning may also be important in setting the transport of the ACC. It has been argued that the eastward momentum gained at the surface is communicated down to bottom water through buoyancydriven overturning, where a westward topographic form stress can then limit the flow (Gent et al. 2001; Hallberg and Gnanadesikan 2001). For an illustration of the different processes by which momentum is transferred downward in the ACC, see Fig. 1 of Hallberg and Gnanadesikan (2001). Diapycnal overturning also plays a key role in setting the stratification, which directly affects the transport under eddy-saturated flow. Therefore, QG models of the ACC are limited because they explicitly ignore thermodynamic effects and cannot simulate overturning.

The other shortcoming with QG channel models is that they omit the role played by ocean basins to the north of the ACC. It is possible that the gyre circulations in these basins (presumably controlled by Sverdrup balance) modify the ACC transport as proposed by Baker (1982) and more recently by Nadeau and Straub (2009). The role of gyres may also be a factor in accounting for discrepancies between coarse-resolution global models and eddy-resolving channel models.

\section{c. Scope of present work}

The dynamical mechanisms controlling the ACC remain a topic of debate. However, emerging evidence from eddy-permitting models (Hallberg and Gnanadesikan 2006), satellite observations (Meredith and Hogg 2006), and in situ ocean observations (Böning et al. 2008; Gille 2008) supports the concept that eddy saturation plays a considerable role in the ACC. With this premise, we use an ocean model that has been previously demonstrated to produce a flow in the eddy-saturated parameter regime. We examine the effect of using the relative 
velocity stress parameterization upon the large-scale flow in this model. The results are presented in terms of the three main flow features: power input, eddy activity, and circumpolar transport. Their dependence upon stress parameterization is examined.

\section{Model}

The numerical experiments in this work were carried out using the quasigeostrophic coupled model (Q-GCM). A full description of the model and the equations of motion are given in the Q-GCM users' guide (Hogg et al. 2003a) and in Hogg et al. (2003b). This section presents a brief overview of the model.

The model consists of three QG ocean layers, three QG atmosphere layers, an ocean mixed layer, and an atmosphere mixed layer. In this study, only the ocean component and the atmosphere mixed layer are permitted to evolve dynamically; the three QG atmosphere layers are set to a fixed sinusoidal pressure profile. The model is configured to an ACC-like channel, with periodic east-west boundaries. The mean Coriolis parameter is set to that of $55^{\circ} \mathrm{S}$, and topography is included in the bottom layer of the ocean. This topography is derived from the observed topography of the Southern Ocean (Smith and Sandwell 1997), although it is truncated at $\pm 780 \mathrm{~m}$ from the mean ocean depth (set to $4 \mathrm{~km})$.

One of the main strengths of Q-GCM is its ability to resolve mesoscale flow in the ocean. For the simulations used here, the ocean resolution is set to $10 \mathrm{~km}$. This is smaller than the first and second Rossby radii (33 and $19 \mathrm{~km}$ ), therefore, it can resolve eddy activity [although the chosen stratification generates Rossby radii that are larger than observed values in the Southern Ocean (Houry et al. 1987; see Hogg and Blundell 2006 for a discussion on this)]. The presence of eddies plays an important role in the momentum balance of the ACC, as discussed in section 1b. The present work uses Q-GCM version 1.4, which has been modified to include the option of parameterizing wind stress using the relative velocity between the atmosphere and ocean. Previous versions of Q-GCM used the standard quadratic stress law, which is a function of the atmosphere velocity only. The relative velocity stress parameterization required a new algorithm for determining the mixed layer velocities. This algorithm is outlined in the appendix.

The pressure is prescribed to be sinusoidal in the three QG atmosphere layers to achieve a westerly wind stress. The atmospheric contribution to zonal stress $\tau^{x}$ is therefore approximately sinusoidal in the $y$ direction and is uniform in the $x$ direction. The maximum amplitude of the stress is $\tau^{x}=0.14 \mathrm{~N} \mathrm{~m}^{-2}$ (from the atmosphere alone) in the center of the $y$ domain and goes to zero at the northern and southern boundaries. This profile is set as an approximation to the mean zonal wind stress in the Southern Ocean from the Southampton Oceanography Centre (SOC) climatology of Josey et al. (2002).

The ocean was spun up from an initial state of rest, over approximately $25 \mathrm{yr}$. The time series and time-averaged quantities shown below are based on simulations in a statistically stationary state, after spinup is complete. The time-averaged results are integrated over a period of $50 \mathrm{yr}$ (in most cases from years $70-120$ of a $120-\mathrm{yr}$ simulation), so that short-term variability is removed. Two different simulations are described in this paper. The first simulation, labeled $S_{0}$, formulates wind stress from the atmospheric velocity only, using the stress $\tau_{0}$ defined by Eq. (2). The second simulation, labeled $S_{1}$, uses the relative velocity between atmosphere and ocean-the stress $\tau_{1}$ defined by Eq. (1). The standard parameters used throughout this work are shown in Table 1.

\section{Results}

The differences between the simulations $S_{0}$ and $S_{1}$ are investigated, with particular emphasis on the power input, kinetic energy (KE), and circumpolar transport. One significant difference between the two simulations is the eddy activity, indicated by the kinetic energy. Much of the analysis that follows is centered on the eddy field, and its influence upon the steady state flow.

\section{a. Ekman pumping perturbations}

We begin by comparing the time-averaged ocean Ekman pumping velocity between the two simulations, to illustrate the effect of using the relative velocity stress. Figure 1 shows the time average of Ekman pumping velocity $w_{\mathrm{ek}}$ in simulation $S_{1}$, illustrating a broad-scale pattern due to wind forcing and small-scale perturbations due to the ocean currents. In simulation $S_{0}, w_{\mathrm{ek}}$ depends purely on the atmosphere velocity and therefore varies only in the $y$ direction.

The basin-averaged stress differs between the two simulations by only $2 \%$. However, the perturbations to the $w_{\mathrm{ek}}$ field in Fig. 1 correspond to changes in the ocean stress field of up to $\tau_{\text {diff }} \approx 0.06 \mathrm{~N} \mathrm{~m}^{-2}$, which is a significant fraction of the maximum stress $\tau \approx 0.14 \mathrm{~N} \mathrm{~m}^{-2}$. There is a strong spatial correlation between these perturbations and the time-averaged ocean velocity (shown in Fig. 2a). Thus, the perturbations to the forcing are greatest in regions of high ocean velocity, such as standing eddies and jets.

We propose that the forcing perturbations over eddies and jets have the potential to influence the circumpolar 
TABLE 1. Standard parameter values for simulations.

\begin{tabular}{|c|c|c|c|}
\hline Parameter & Value & Unit & Description \\
\hline$X, Y$ & $(23040,2880)$ & $\mathrm{km}$ & Domain size \\
\hline $\bar{F}_{S}$ & -210 & $\mathrm{~W} \mathrm{~m}^{-2}$ & Mean insolation \\
\hline$\left|\stackrel{s}{F_{S}^{\prime}}\right|$ & 70 & $\mathrm{~W} \mathrm{~m}{ }^{-2}$ & Amplitude of variable insolation \\
\hline$f_{0}$ & $-1.195 \times 10^{-4}$ & $\mathrm{~s}^{-1}$ & Mean Coriolis parameter $\left(55^{\circ} \mathrm{S}\right)$ \\
\hline$\beta$ & $1.313 \times 10^{-11}$ & $\mathrm{~m}^{-1} \mathrm{~s}^{-1}$ & Coriolis parameter gradient $\left(55^{\circ} \mathrm{S}\right)$ \\
\hline$\lambda$ & 35 & $\mathrm{~W} \mathrm{~m}^{-2} \mathrm{~K}^{-1}$ & Sensible and latent heat flux coef \\
\hline$\Delta^{o} x$ & 10 & $\mathrm{~km}$ & Oceanic horizontal grid spacing \\
\hline$\Delta^{o} t$ & 12 & $\min$ & Ocean time step \\
\hline${ }^{o} H_{k}$ & $(300,1100,2600)$ & $\mathrm{m}$ & Ocean layer heights \\
\hline${ }^{o} H_{m}$ & 100 & $\mathrm{~m}$ & Ocean mixed layer height \\
\hline${ }^{o} \rho$ & $1.0 \times 10^{3}$ & $\mathrm{~kg} \mathrm{~m}^{-3}$ & Ocean density \\
\hline${ }^{\circ} C_{p}$ & $4.0 \times 10^{3}$ & $\mathrm{~J} \mathrm{~kg}^{-1} \mathrm{~K}^{-1}$ & Ocean specific heat capacity \\
\hline$g_{k}^{\prime}$ & $(0.05,0.025)$ & $\mathrm{m} \mathrm{s}^{-2}$ & Reduced gravity \\
\hline$A_{2}$ & 0 & $\mathrm{~m}^{2} \mathrm{~s}^{-1}$ & Ocean Laplacian viscosity coef \\
\hline$A_{4}$ & $1.0 \times 10^{10}$ & $\mathrm{~m}^{4} \mathrm{~s}^{-1}$ & Ocean biharmonic viscosity coef \\
\hline${ }^{o} K_{2}$ & 380 & $\mathrm{~m}^{2} \mathrm{~s}^{-1}$ & Laplacian temperature diffusion coef \\
\hline${ }^{o} K_{4}$ & $1.0 \times 10^{11}$ & $\mathrm{~m}^{4} \mathrm{~s}^{-1}$ & Biharmonic temperature diffusion coef \\
\hline$\alpha_{\mathrm{bc}}$ & 5.0 & Nondimensional & Mixed BC coefficient \\
\hline$\delta_{\mathrm{ek}}$ & 1.0 & $\mathrm{~m}$ & Bottom Ekman layer thickness \\
\hline${ }^{o} R_{\mathrm{d} 1},{ }^{o} R_{\mathrm{d} 2}$ & $(33,19)$ & $\mathrm{km}$ & Ocean baroclinic Rossby radii (derived) \\
\hline$\Delta^{a} x$ & 80 & $\mathrm{~km}$ & Atmospheric horizontal grid spacing \\
\hline$\Delta^{a} t$ & 1 & $\min$ & Atmosphere time step \\
\hline${ }^{a} H_{m}$ & 1000 & $\mathrm{~m}$ & Atmosphere mixed layer height \\
\hline${ }^{a} \rho$ & 1.0 & $\mathrm{~kg} \mathrm{~m}^{-3}$ & Atmosphere density \\
\hline${ }^{a} K_{2}$ & $2.7 \times 10^{4}$ & $\mathrm{~m}^{2} \mathrm{~s}^{-1}$ & Laplacian temperature diffusion coef \\
\hline${ }^{a} K_{4}$ & $3.0 \times 10^{14}$ & $\mathrm{~m}^{4} \mathrm{~s}^{-1}$ & Biharmonic temperature diffusion coef \\
\hline${ }^{a} C_{p}$ & 1000 & $\mathrm{~J} \mathrm{~kg}^{-1} \mathrm{~K}^{-1}$ & Atmosphere specific heat capacity \\
\hline$C_{d}$ & $1.3 \times 10^{-3}$ & Nondimensional & Drag coef \\
\hline
\end{tabular}

transport, because eddies are crucial in setting the momentum balance of the ACC.

\section{b. Power input}

The differences in forcing between simulations $S_{0}$ and $S_{1}$ (Fig. 1) will alter the power input, as proposed by Duhaut and Straub (2006). Figures 2a-c show a comparison between the spatial distributions of the top QG layer ocean velocity, the power distribution $P_{0}$, and the power difference $P_{\text {diff }}$ [given by Eq. (6)], respectively. All three quantities are time averaged over $50 \mathrm{yr}$. There is a clear correlation between the ocean velocity and
$P_{\text {diff }}$, indicating that the power reduction caused by using $\boldsymbol{\tau}_{1}$ is greatest over jets and standing eddies.

Figure 3 shows the spatially averaged power input time series from each simulation (solid lines). Both curves show significant interdecadal variability, as observed in a previous study of the Southern Ocean using Q-GCM (Hogg and Blundell 2006). The amplitude of the variations is roughly a factor of 2 larger in simulation $S_{1}$ than in simulation $S_{0}$, indicating enhanced variability under the relative velocity stress. Power input is greater in simulation $S_{0}$ than in simulation $S_{1}$, as shown in Fig. 3 (cf. the two solid curves). This result is expected and fits

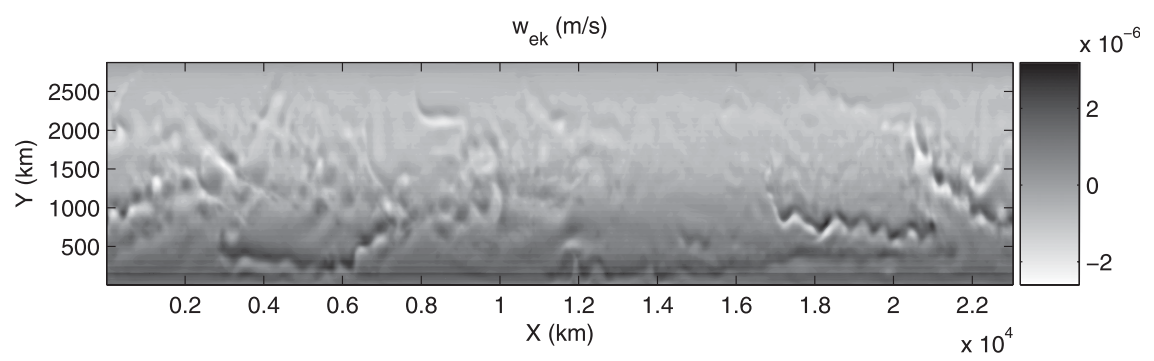

FIG. 1. Average Ekman pumping velocity $w_{\mathrm{ek}}$ in simulation $S_{1}$, showing a combination of the broad-scale positive contributions from the wind forcing and small-scale perturbations resulting from ocean currents. 
(a) $\mathrm{lu}_{\mathrm{o}} \mid(\mathrm{m} / \mathrm{s})$

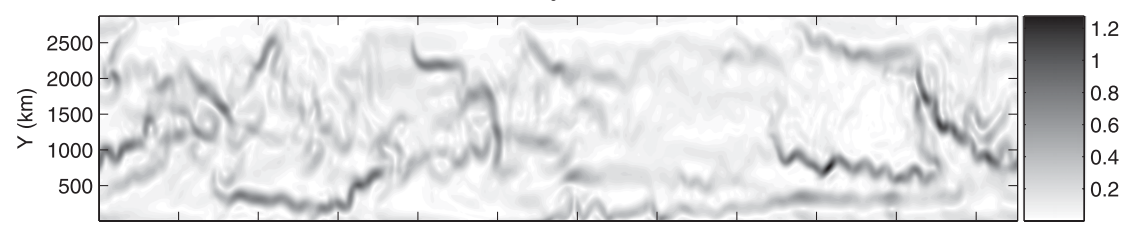

(b) $\mathrm{P}_{0}\left(\mathrm{~W} / \mathrm{m}^{2}\right)$

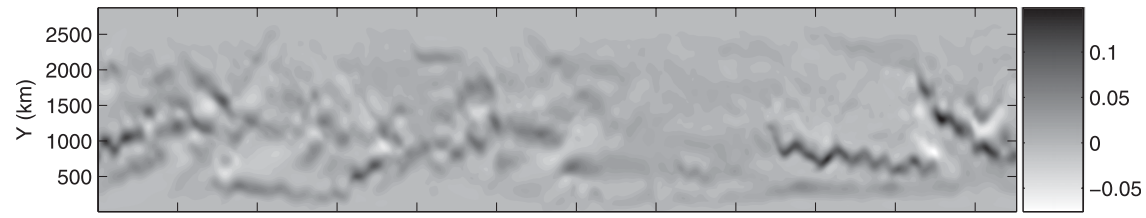

(c) $P_{\text {diff }}\left(W / m^{2}\right)$

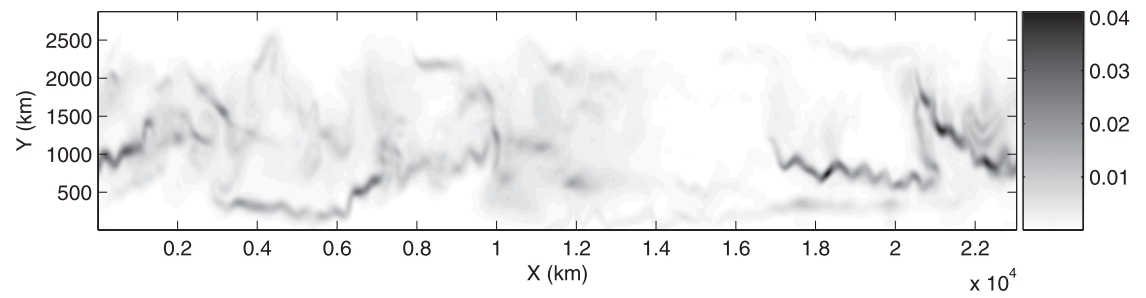

FIG. 2. (a) Time-averaged upper-ocean velocity $\left|u_{o}\right|$, (b) $P_{0}$, and (c) $P_{\text {diff }}$ as calculated from simulation $S_{1}$, with each quantity time averaged over 50 yr. Both $P_{0}$ and $P_{\text {diff }}$ are large in magnitude above regions of high velocity.

with the predictions of Duhaut and Straub (2006). The time- and space-averaged power input from simulation $S_{0}$ is $\left\langle P_{0}\right\rangle=7.83 \times 10^{-3} \mathrm{~W} \mathrm{~m}^{-2}$, whereas that of simulation $S_{1}$ is $\left\langle P_{1}\right\rangle=6.39 \times 10^{-3} \mathrm{~W} \mathrm{~m}^{-2}$. If $\left\langle P_{\text {diff }}\right\rangle$ is estimated from the difference of these two averages, one obtains

$$
\left\langle P_{\text {diff }}\right\rangle=1.44 \times 10^{-3} \mathrm{~W} \mathrm{~m}^{-2},
$$

or a relative change of

$$
\frac{\left\langle P_{\text {diff }}\right\rangle}{\left\langle P_{0}\right\rangle}=0.18
$$

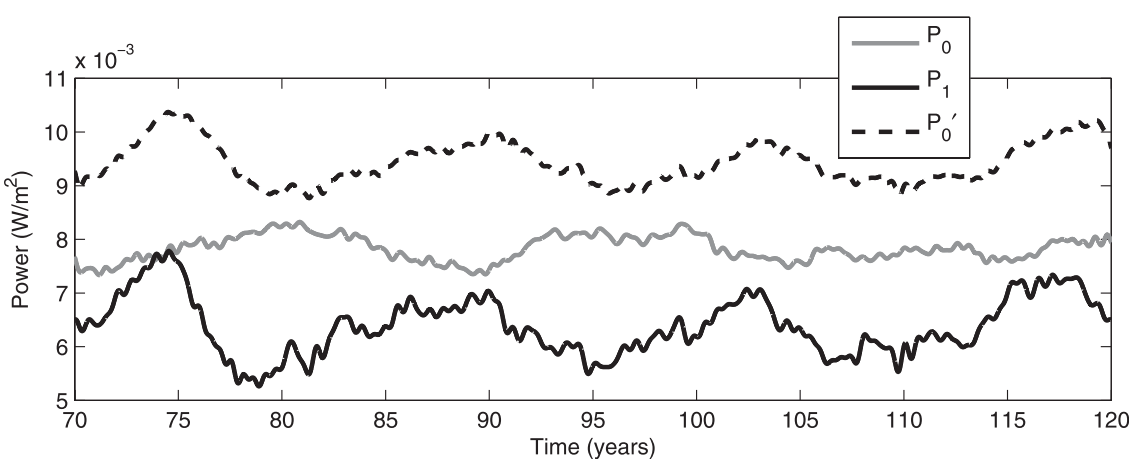

FIG. 3. Time series of the area-averaged power input. Here, $P_{0}$ and $P_{1}$ (solid curves), as well as $P_{0}^{\prime}$ (dashed curve; calculated from simulation $S_{1}$ velocities and $S_{0}$ stress). The above curves were smoothed using a low-pass Fourier filter, with a cutoff frequency of $0.5 \mathrm{yr}^{-1}$. This filtering method applies to all of the subsequent time series presented in this paper. 
TABLE 2. Comparison of circumpolar transport between simulations $S_{0}$ and $S_{1}$.

\begin{tabular}{ccccc}
\hline \hline & \multicolumn{4}{c}{ Circumpolar transport (Sv) } \\
\cline { 2 - 5 } Simulation & Layer 1 & Layer 2 & Layer 3 & Total \\
\hline$S_{0}$ & 71.6 & 67.7 & -7.0 & 132 \\
$S_{1}$ & 84.8 & 87.0 & -1.8 & 170 \\
\hline
\end{tabular}

$$
\left\langle P_{\text {diff }}^{\prime}\right\rangle=3.05 \times 10^{-3} \mathrm{~W} \mathrm{~m}^{-2},
$$

or a relative change of

$$
\frac{\left\langle P_{\text {diff }}^{\prime}\right\rangle}{\left\langle P_{0}^{\prime}\right\rangle}=0.32
$$

The observation that $P_{0}^{\prime}$ is higher than $P_{0}$ implies a higher layer 1 ocean velocity in simulation $S_{1}$ (since $\tau_{0}$ is the same for both estimates). This result is counterintuitive, given that wind stress and power input are systematically reduced in simulation $S_{1}$. Duhaut and Straub (2006) found the opposite trend in their gyre model, where the use of $\tau_{1}$ reduced the mean ocean velocity and therefore reduced $P_{0}$. This distinction between our ACC-like model and the gyre model can be explained by an eddy-damping effect, combined with the eddy-saturated regime in this model.

It is also useful to split $\left\langle P_{\text {diff }}^{\prime}\right\rangle$ into parts associated with the mean flow and the transient velocity field. The mean flow contribution to $\left\langle P_{\text {diff }}^{\prime}\right\rangle$ is calculated as $\left\langle\mathbf{u}_{o}\right\rangle \cdot\left(\left\langle\boldsymbol{\tau}_{0}\right\rangle-\right.$ $\left.\left\langle\boldsymbol{\tau}_{1}\right\rangle\right)$, using the $\left\langle\mathbf{u}_{o}\right\rangle$ field from simulation $S_{1}$. We find that the mean flow contribution to $\left\langle P_{\text {diff }}^{\prime}\right\rangle$ is $8.8 \times 10^{-4} \mathrm{~W} \mathrm{~m}^{-2}$ or $29 \%$ of the total $\left\langle P_{\text {diff }}^{\prime}\right\rangle$. Thus, the majority of $\left\langle P_{\text {diff }}^{\prime}\right\rangle$ comes from the transient velocity field.

\section{c. Circumpolar transport}

The layer 1 ocean velocity is larger in simulation $S_{1}$ than simulation $S_{0}$, as inferred from power input measurements. This difference is also reflected in the circumpolar transport [as shown in Table 2, the total circumpolar transport in simulation $S_{1}$ is $170 \mathrm{~Sv}(1 \mathrm{~Sv} \equiv$ $10^{6} \mathrm{~m}^{3} \mathrm{~s}^{-1}$ ), compared with $132 \mathrm{~Sv}$ in simulation $\left.S_{0}\right]$. In both simulations, the transport in the bottom layer is negative (i.e., westward) and is very small compared with the eastward transport in the upper two layers. Thus, the geostrophic transport referenced to the bottom is the dominant mode of circumpolar flow in both simulations.

The time-averaged layer 1 streamfunctions of simulations $S_{0}$ and $S_{1}$ are shown in Figs. 4a,b, respectively. Figures $4 \mathrm{c}, \mathrm{d}$ show instantaneous snapshots of simulations $S_{0}$ and $S_{1}$, respectively, with the snapshots taken at $t=120 \mathrm{yr}$. The instantaneous streamfunction in each case illustrates the presence of transient eddies. Al- though the magnitudes of transport are different in each case, the pattern of flow is very similar. A comparison with the topography anomaly shown in Fig. 4e demonstrates that the streamfunction is very closely linked to topography. The standing jets shown in Figs. 4a,b tend to meander around regions of elevated topography and are stronger above valleys on the ocean floor.

One of the limitations of this model is that it represents Drake Passage as a region of elevated underwater topography, rather than a coastal barrier. This permits a substantial portion of flow across regions of topography that represent land barriers (as shown in Figs. 4a,b). We estimate that approximately half of the circumpolar transport in our model flows through the band of the Drake Passage, whereas the remainder flows across would-be land barriers. However, this estimate is very sensitive to the exact choice of northern and southern limits for the Drake Passage. This sensitivity is especially strong in the bottom layer, where there are strong recirculations in this region of the model. Because the barriers themselves are not well defined, a precise estimate of transport through Drake Passage is beyond the scope of this model.

\section{1) EDDY SATURATION}

The theory of eddy saturation states that the circumpolar transport of the ACC is strongly influenced by the vertical transport of momentum resulting from eddies (section 1b). In an eddy-saturated state, geostrophic transport relative to the bottom is only weakly (if at all) related to the wind stress. Some models have found that eddy saturation is associated only with weak wind forcing and that stronger wind forcing leads to the transport increasing as a function of stress (Johnson and Bryden 1989; Tansley and Marshall 2001). However, previous studies of the ACC, using Q-GCM, have shown that this model behaves in an eddy-saturated manner, even under substantial wind forcing (Hogg and Blundell 2006; Meredith and Hogg 2006). This leads one to question why the transport should be $38 \mathrm{~Sv}$ larger under the $\tau_{1}$ stress than the $\tau_{0}$ stress. One possible explanation of the transport difference is that simulation $S_{1}$ is not actually in an eddy-saturated state. To test this hypothesis, simulations $S_{1}$ and $S_{0}$ were extended for a further $30 \mathrm{yr}$, with the specified atmospheric pressure gradient decreased so that the peak wind stress was reduced by $25 \%$.

The reduced wind stress forcing did not significantly reduce the transport in either simulation $S_{0}$ or $S_{1}$. Figure 5a shows a time series of transport from simulation $S_{0}$ (black), with the extended simulation under the reduced stress $\tau_{0}$ (gray). The transport appears to fall in the first 2-3 yr of the weakened stress regime; however, the average transport over the $30-\mathrm{yr}$ period of the extended simulation is 
(a) $\mathrm{S}_{0}$ : Mean Streamfunction

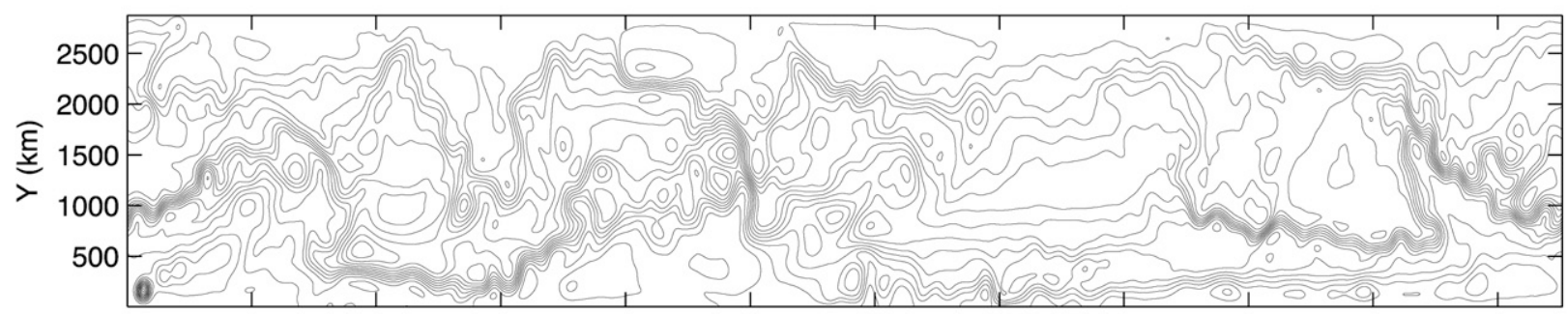

(b) $\mathrm{S}_{1}$ : Mean Streamfunction

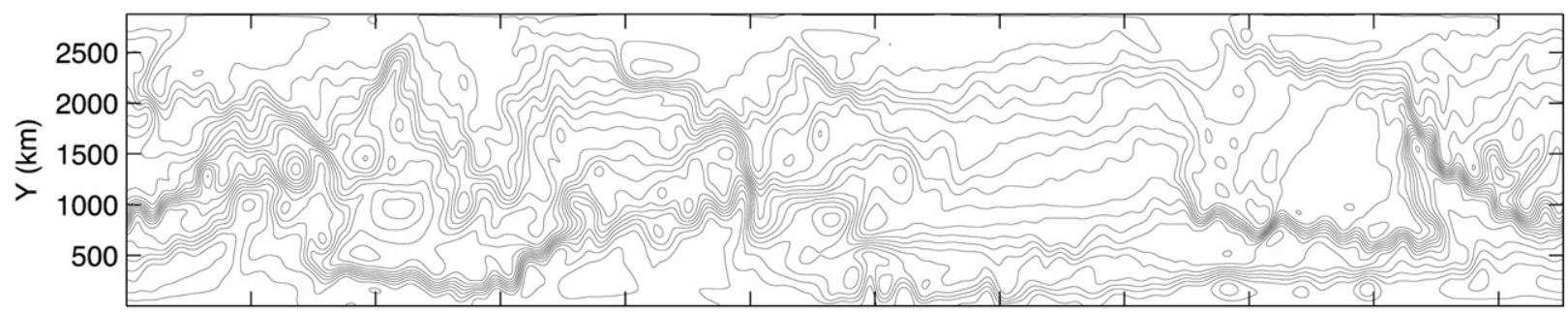

(c) $\mathrm{S}_{0}$ : Instantaneous Streamfunction

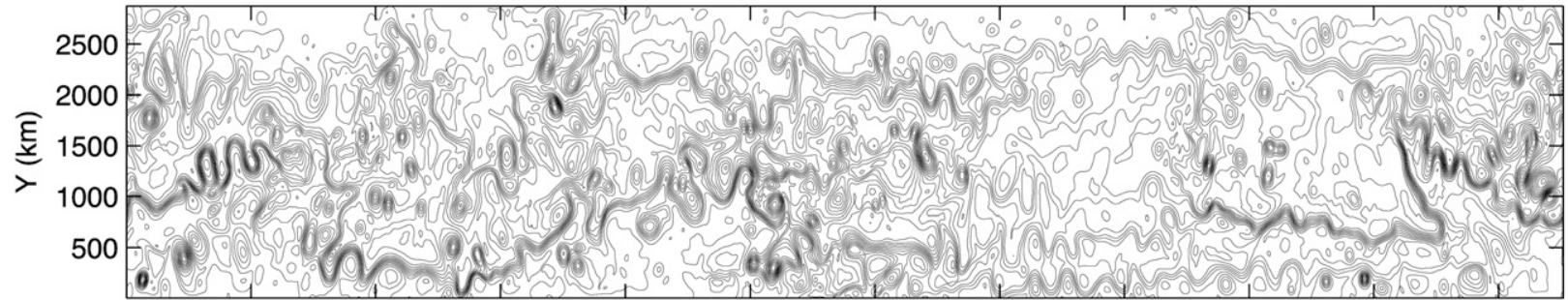

(d) $S_{1}$ : Instantaneous Streamfunction

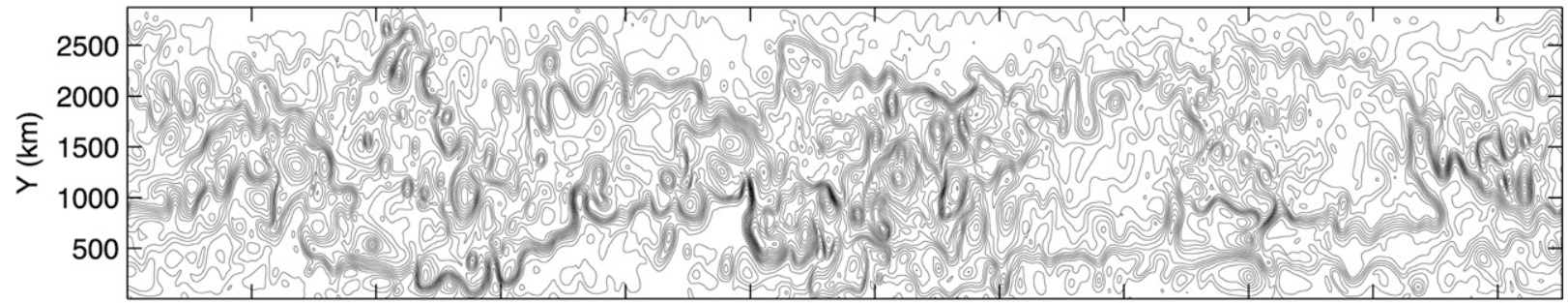

(e) Topography Anomaly (m)

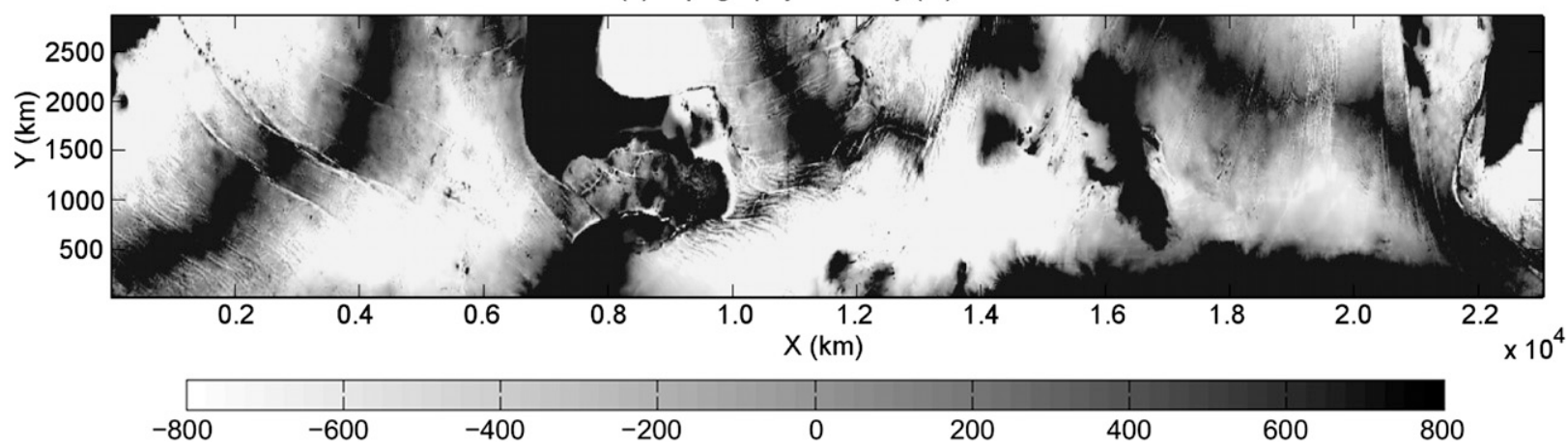

FIG. 4. The layer 1 mean streamfunctions of (a) $S_{0}$ and (b) $S_{1}$; instantaneous layer 1 streamfunctions of (c) $S_{0}$ and (d) $S_{1}$ taken at $t=$ $120 \mathrm{yr}$ in each case. (a)-(d) The plots' contour interval is $5 \mathrm{~Sv}$. (e) The topography anomaly is also shown. The direction of the flow is similar in both simulations and is closely linked to the topography. Jets appear to meander around elevated topography and are stronger above valleys. 
(a) Standard Stress

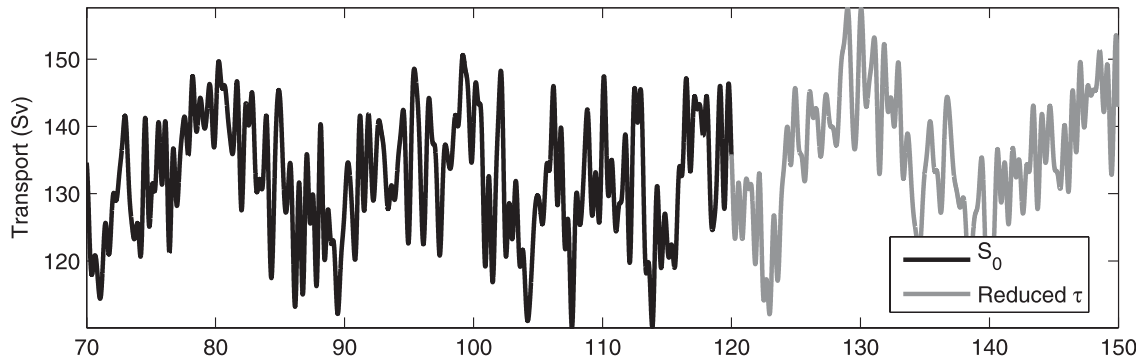

(b) Relative Velocity Stress

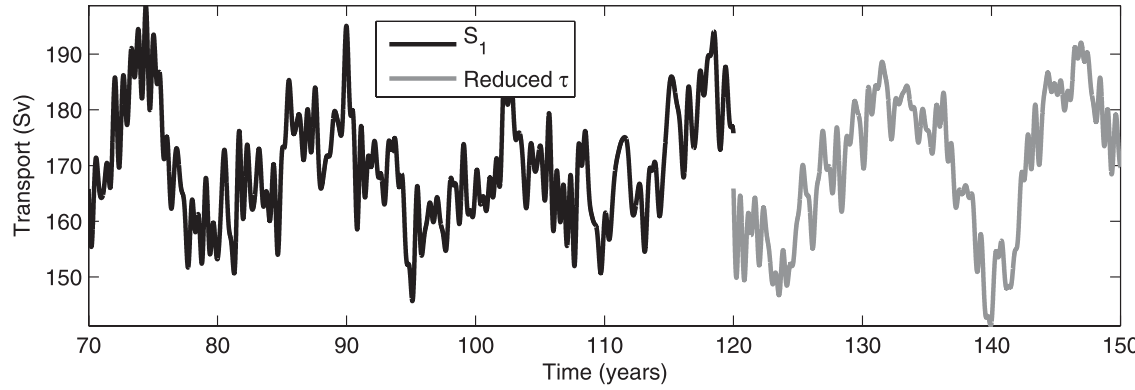

FIG. 5. Circumpolar transport plotted as a function of time. (a) The standard stress regime, comparing simulation $S_{0}$ (black) with a $25 \%$ reduction of stress (gray). (b) The relative velocity stress regime, comparing simulation $S_{1}$ (black) with a $25 \%$ reduction in wind stress (gray). The apparent discontinuity between the black and gray curves is caused by the low-pass filters applied to each trend separately. In both cases, the transport is largely unaffected by the reduction in wind stress.

very close to that of simulation $S_{0}$. This strongly supports the hypothesis that simulation $S_{0}$ is in an eddy-saturated state. Extending simulation $S_{1}$ yields similar results. Figure $5 \mathrm{~b}$ shows a time series of the transport from simulation $S_{1}$, with the extended simulation under the reduced stress. Once again, the transport drops for the first 2-3 yr and then returns to a similar equilibrium as simulation $S_{1}$. This trend confirms that simulation $S_{1}$ is also in an eddy-saturated state, implying that there must be an alternative explanation for the discrepancy in transport between simulations $S_{0}$ and $S_{1}$. One possibility is the eddy-damping effect, which is explored in the following section.

\section{2) EDDY-DAMPING EFFECT}

The contribution of the ocean velocity to the relative velocity wind stress acts to damp high-velocity flows (as discussed in section 1a). This damping implies that the eddy field should be suppressed by the wind stress in simulation $S_{1}$ (relative to that in simulation $S_{0}$ ). This difference in eddy activity plays a role in the momentum balance of the circumpolar flow. For simplicity, consider the current to be a combination of a zonal mean flow and a transient eddy field. The stress drives the zonal flow, which develops an eddy field through baroclinic instability. The eddy field enhances the vertical transport of momentum via interfacial form stress, which in turn leads to topographic form stress (the primary momentum sink). A faster zonal flow will create a more vigourous eddy field, leading to a greater topographic form stress. The steady-state flow is that in which momentum input at the surface is balanced by topographic form stress.

Consider the response of the eddy fields of the two simulations, given the same zonal mean flow. In simulation $S_{1}$, the eddy field should be weaker than in simulation $S_{0}$ under the same zonal velocity, because of the eddy damping effect. Conversely, simulation $S_{1}$ would have to reach a higher zonal velocity than simulation $S_{0}$ to generate the same eddy activity. Since topographic form stress is controlled by the level of eddy activity, this would mean that simulation $S_{1}$ should have a higher equilibrium zonal velocity, and thus a larger volume transport. Therefore we argue on qualitative grounds that the eddy damping effect is likely to be responsible for the observed increase in circumpolar transport in simulation $S_{1}$.

\section{d. Eddy kinetic energy}

If eddy damping plays the role hypothesized previously, then there should be a decrease in mesoscale eddy activity in simulation $S_{1}$. Kinetic energy serves as a useful measure of the eddy activity because eddies have relatively large velocities compared with the mean 
TABLE 3. Layer $1 \mathrm{KE}$, showing the contributions of zonal mean flow, standing eddies, transient eddies, and the total. Simulation $S_{0}$ has a greater eddy KE from both standing and transient components, whereas simulation $S_{1}$ has a higher zonal mean KE.

\begin{tabular}{ccccc}
\hline \hline \multirow{2}{*}{ Simulation } & \multicolumn{4}{c}{$\mathrm{KE}\left(\times 10^{4} \mathrm{~J} \mathrm{~m}^{-2}\right)$} \\
\cline { 2 - 5 } & $\begin{array}{c}\text { Zonal } \\
\text { mean }\end{array}$ & $\begin{array}{c}\text { Standing } \\
\text { eddies }\end{array}$ & $\begin{array}{c}\text { Transient } \\
\text { eddies }\end{array}$ & Total \\
\hline$S_{0}$ & 0.14 & 0.62 & 2.50 & 3.26 \\
$S_{1}$ & 0.19 & 0.55 & 2.02 & 2.77 \\
\hline
\end{tabular}

flow. For the purpose of estimating the eddy KE, we assume that the flow consists of three components: zonal mean flow, standing eddies, and transient eddies. The time mean velocity field is assumed to be made up of a zonal mean flow and standing eddies, while the remainder of the velocity field is treated as the transient eddy field. This simplified treatment does not distinguish between transient eddies and meandering jets; however, it does allow us to compare the eddy activity between the two simulations. Table 3 shows the zonal mean, standing eddy, and transient eddy KE from each simulation. Both the standing eddy and transient eddy components of $\mathrm{KE}$ are smaller in simulation $S_{1}$ than in simulation $S_{0}$. This is consistent with the theory that eddy damping resulting from $\boldsymbol{\tau}_{1}$ suppresses eddy activity. By contrast, the zonal mean KE is larger in simulation $S_{1}$ than in simulation $S_{0}$, which reflects the greater circumpolar flow.
Figure 6a shows the time series of eddy KE in the top layer (both standing and transient components), comparing simulations $S_{0}$ and $S_{1}$. The higher eddy KE in simulation $S_{0}$ supports the hypothesis that simulation $S_{1}$ has a weaker eddy field, resulting from the eddydamping effect. However, the potential energy (PE) is higher in simulation $S_{1}$ (Fig. 6b). The higher PE is associated with a larger interfacial tilt across the channel, consistent with greater zonal flow in simulation $S_{1}$.

\section{Discussion}

The simulations presented in this paper were conducted to investigate a subtlety in the parameterization of wind stress in a model of the Southern Ocean. The subtlety under investigation is the relative velocity stress scheme, where stress is written as a quadratic function of the difference between the atmosphere and ocean velocity (in contrast to schemes that use atmosphere velocity alone). The relative velocity stress scheme does not alter the magnitude of the stress significantly; however, it has been shown to reduce the wind power input to the ocean, when applied to a model of ocean gyres (Duhaut and Straub 2006; Zhai and Greatbatch 2007).

The present work has confirmed that power input to the modeled ACC is reduced under relative velocity stress. The difference in power is $32 \%$ of the total power input, which is similar to the $20 \%-35 \%$ reduction found in gyres (Duhaut and Straub 2006; Zhai and Greatbatch
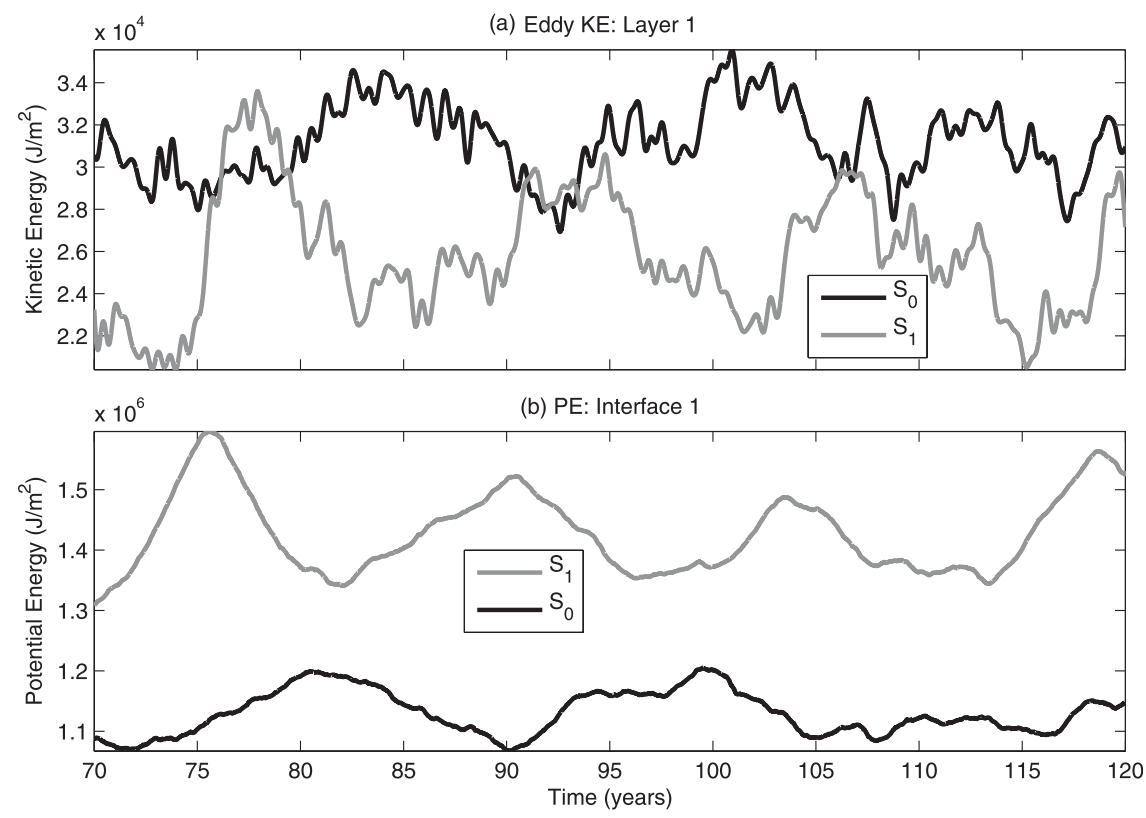

FIG. 6. (a) Time series of layer 1 eddy KE for each simulation. The lower eddy KE in simulation $S_{1}$ indicates a weaker eddy field. (b) Potential energy at the upper interface. 
2007). This result is achieved primarily because the ocean velocity contribution systematically reduces power input over eddies.

A further consideration in this work is the impact of the relative velocity stress upon the dynamics of the ACC. With a lower power input to the ocean, one would expect the transport and the eddy activity to decrease. Although the eddy KE does decrease as expected, we find that transport counterintuitively increases under the relative velocity stress.

The increase in transport found in our ACC model is distinct from the results of gyre models and is a consequence of two main factors. The first factor is eddy damping, where the contribution of the ocean velocity to the stress aligns in the opposite direction to the ocean velocity (Dewar and Flierl 1987; Zhai and Greatbatch 2007; Xu and Scott 2008). This damping strongly affects high-velocity flows, especially eddies, and its overall effect is to weaken the eddy field. The second factor is eddy saturation, where the momentum balance of the circumpolar current is moderated by eddy activity. Under the eddy-damping effect, the flow reaches a higher zonal velocity before the eddy field reaches the point of saturation. Thus, the combination of eddy saturation and eddy damping means that transport is greater under the relative velocity stress, despite the reduced power input. This new subtlety has not been predicted by previous studies of the relative velocity stress because those studies investigated gyre flows, which are limited by different processes.

The result that eddy damping increases the circumpolar transport has illuminated another reason why it is dynamically important to resolve eddies in a Southern Ocean model. The importance of eddies to the momentum balance of the ACC has been well established by previous studies. Eddies transfer momentum downward through interfacial form stress, resulting in topographic form stress that limits the flow (as discussed in section 1b). In coarse-resolution models of the ACC, transport increases monotonically as a function of zonal wind stress (Gent et al. 2001; Fyfe and Saenko 2005). Moreover, the direction of the flow is more zonal in coarseresolution models of the ACC than in eddy-resolving models (Hallberg and Gnanadesikan 2006). Thus, it is reasonable to expect that the relative velocity stress scheme would play a different role in coarse-resolution models.

We have run additional tests to ascertain ways in which the effect of the relative velocity stress differs with coarse-resolution models. These tests use the same domain and forcing fields, but with $90-\mathrm{km}$ grid length (increased from $10 \mathrm{~km}$ ). The other primary difference is that the low-resolution cases have a high horizontal diffusion of potential vorticity (PV; compared with biharmonic diffusion of relative velocity in the eddy-resolving cases) used in part for numerical stability but also as an approximation to the eddy parameterization schemes used in most climate models (see, e.g., Gent et al. 1995). At low resolution the model ceases to be eddy saturated; increases in wind stress are linearly proportional to the transport (consistent with coarse-resolution climate models; e.g., Fyfe and Saenko 2005). However, perturbations that are eddy-like still have some effect in transferring vertical momentum; consequently, circumpolar transport remains slightly larger in the relative velocity stress case (although the effect is relatively small). If horizontal diffusion of PV is increased further, one finds a parameter regime in which the relative velocity stress scheme makes no difference to circumpolar transport but decreases power input. These results demonstrate that coarse-resolution models of the ACC have a weaker response to the relative velocity stress scheme than eddyresolving models.

A revised estimate of wind power input has ramifications for the global ocean energy budget. The wind power input to the global oceans has been estimated at $0.88 \mathrm{TW}$, with approximately $0.6 \mathrm{TW}$ of this power input occurring in the Southern Ocean (Wunsch 1998). In our model, the power input is reduced by $32 \%$ under the relative velocity stress. If this result were extrapolated onto the entire Southern Ocean, it would translate into a power difference of approximately $0.2 \mathrm{TW}$. However, our model aims to represent only the fastest-flowing region of the Southern Ocean, namely, the ACC; therefore, this extrapolation of the power difference is likely to be an overestimate. Hughes and Wilson (2008) estimated the difference in power input resulting from the relative velocity stress from scatterometer data. They found a global reduction in power of $0.19 \mathrm{TW}$, with 0.06 TW occurring in the Southern Ocean. Revised estimates of the Southern Ocean power input also have implications for the energetics of the meridional-overturning circulation because wind power input represents a large fraction of the total mixing energy of the overturning, estimated at 2 TW (Munk and Wunsch 1998).

As noted by other authors (Xu and Scott 2008; Hughes and Wilson 2008), the sensitivity of the circulation to small-scale wind stress poses problems for forcing an ocean model. One possibility is to use observations of wind stress to force an ocean model. However, a scatterometerderived wind stress explicitly accounts for the relative velocity between the atmosphere and ocean. If such a wind stress field were applied to an ocean model that had its own freely evolving velocity field, the power reduction observed here would not be accounted for, since the stress would no longer correlate with the mesoscale 
ocean velocity field. This implies that the eddy-damping effect would no longer influence the transient eddy field. The resulting power input would be overestimated and the circumpolar transport underestimated.

Not all of the power difference would be ignored under such a forcing scheme. Although the majority of the $\mathrm{KE}$ of the flow is made up of transient features (Table 3), there is a significant proportion of the flow that is essentially time independent, including standing eddies and jets. The power input delivered to these timeindependent components could be accurately represented by a scatterometer-forced ocean model. However, if the flow is dominated by transient components, then a scatterometer-forced ocean model would ignore the majority of the power reduction resulting from the relative velocity stress. Scatterometer studies have found this to be the case. $\mathrm{Xu}$ and Scott (2008) estimated that $72 \%$ of the power reduction comes from the transient ocean velocity contribution, while Hughes and Wilson (2008) found a similar estimate of $75 \%$. In our model, $71 \%$ of the power difference was due to transient flow. Based on these estimates, approximately three-quarters of the power reduction would be ignored under a scatterometerforced ocean model. A scatterometer-derived wind stress forcing would, thus, behave more like the standard stress than the relative velocity stress.

The results shown here are based on an idealized QG model, which does not include thermodynamic effects. It has been argued that diapycnal overturning may influence the transport of the ACC. Thus, the eddy-saturated state observed in this model is an incomplete picture of the ACC. It must also be noted that the circumpolar transport in this model is greatly affected by the stratification (Hogg and Blundell 2006). Therefore, the reduction in transport observed under the standard stress (compared with relative velocity stress) must be considered among a range of other factors limiting the transport.

Another way in which stress is coupled to small-scale ocean features is through interactions with SST gradients (O'Neill et al. 2003; Nonaka and Xie 2003; Chelton et al. 2004). The coupling between SST gradients and stress has recently been modeled in Q-GCM, adding a simple temperature dependence to the quadratic stress law (Hogg et al. 2009). Hogg et al. investigated the effect of a temperature-dependent stress upon a double-gyre model. They found that the temperature-dependent stress reduced the large-scale flow of the gyres in their model. We have repeated these simulations with a channel model, and surprisingly find that the transport, kinetic energy, and power input are unaffected by the temperature-dependent stress in this Southern Ocean configuration (in contrast to the relative velocity stress). This null result has not been included in this paper; however, a more detailed discussion of these results is given by Hutchinson (2008).

\section{Conclusions}

This study was designed to explore the impact of parameterizing wind stress as a function of the relative velocity between the atmosphere and ocean in a model representing the Antarctic Circumpolar Current (ACC). This parameterization was investigated with reference to a standard parameterization of wind stress, depending on atmospheric velocity only.

The relative velocity stress scheme acts to decrease power input to the channel, when compared with the standard stress scheme. This occurs because the ocean contribution to the relative velocity stress is always opposite in direction to the ocean velocity. Thus, the power input is monotonically reduced and the reduction is greatest over eddies and jets. These results confirm that the relative velocity stress reduces power input in the Southern Ocean, in a similar proportion to that found in the midlatitude ocean gyres.

The circumpolar transport is greater under the relative velocity stress, despite the reduced power input. This counterintuitive result occurs because of the combination of eddy saturation and eddy damping. The changes in transport and power input can only be observed in a model that resolves eddies, providing additional reasons as to why coarse-resolution models cannot capture the dynamics of the ACC.

Acknowledgments. Our thanks to David Straub and an anonymous reviewer, whose constructive comments helped to substantially improve the manuscript, and to Chris Wilson and Chris Hughes, who helped to formulate the relative velocity stress scheme in Q-GCM. Marshall Ward and Rob Scott provided comments on a draft of this manuscript. This work was conducted while DKH was studying Honours at RSES, with the support of an A. L. Hales Scholarship. AMH was supported by an ARC Grant (DP0877824). Numerical computations were supported by the National Facility of the National Computational Infrastructure.

\section{APPENDIX}

\section{Relative Velocity Stress Formulation}

The algorithm for calculating wind stress under the standard scheme is in the Q-GCM users' guide (Hogg et al. 2003a). The relative velocity stress requires a different algorithm, outlined below. Wind stress is a quadratic 
function of the difference between the atmosphere mixed layer velocity ${ }^{a} \mathbf{u}_{m}$ and the ocean mixed layer velocity ${ }^{o} \mathbf{u}_{m}$. We show how to deduce these (unknown) mixed layer velocities from the (known) geostrophic velocities of the atmosphere and ocean. Starting from the stress equation,

$$
\left({ }^{a} \tau^{x},{ }^{a} \tau^{y}\right)=C_{d}\left|{ }^{a} \mathbf{u}_{m}-{ }^{o} \mathbf{u}_{m}\right|\left({ }^{a} u_{m}-{ }^{o} u_{m},{ }^{a} v_{m}-{ }^{o} v_{m}\right),
$$

where $\left({ }^{a} \tau^{x},{ }^{a} \tau^{y}\right)$ are the atmosphere dynamic stress components in the $(x, y)$ directions. ${ }^{1}$ The atmosphere mixed layer velocity components ${ }^{a} u_{m}$ and ${ }^{a} v_{m}$ are given by the sum of geostrophic and Ekman transport components,

$$
\begin{aligned}
& { }^{a} u_{m}={ }^{a} u_{1}-\frac{{ }^{a} \tau^{y}}{{ }^{a} H_{m} f_{0}} \text { and } \\
& { }^{a} v_{m}={ }^{a} v_{1}+\frac{{ }^{a} \tau^{x}}{{ }^{a} H_{m} f_{0}},
\end{aligned}
$$

where $\left({ }^{a} u_{1},{ }^{a} v_{1}\right)$ are the layer 1 atmosphere velocity components, $f_{0}$ is the mean Coriolis parameter, and ${ }^{a} H_{m}$ is the mixed layer height. The ocean mixed layer velocity components are similar in form to their atmospheric counterparts,

$$
\begin{aligned}
& { }^{o} u_{m}={ }^{o} u_{1}+\frac{{ }^{o} \tau_{1}^{y}}{{ }^{o} H_{m} f_{0}} \text { and } \\
& { }^{o} v_{m}={ }^{o} v_{1}-\frac{{ }^{o} \tau_{1}^{x}}{{ }^{o} H_{m} f_{0}}
\end{aligned}
$$

where the superscript " $O$ " denotes oceanic quantities. For simplicity, we define the parameters $U, a$, and $b$ as

$$
\begin{aligned}
U & \equiv\left|{ }^{a} \mathbf{u}_{m}-{ }^{o} \mathbf{u}_{m}\right| \geq 0, \\
a & \equiv \frac{C_{d}}{{ }^{a} H_{m} f_{0}}, \quad \text { and } \\
b & \equiv \frac{\rho_{a} C_{d}}{\rho_{o}^{o} H_{m} f_{0}} \approx 10^{-2} a .
\end{aligned}
$$

We can then rewrite Eq. (A1) as

$$
\left({ }^{a} \tau^{x},{ }^{a} \tau^{y}\right)=C_{d} U\left({ }^{a} u_{m}-{ }^{o} u_{m},{ }^{a} v_{m}-{ }^{o} v_{m}\right)
$$

\footnotetext{
${ }^{1}$ We use dynamic stress (stress divided by reference density) in this algorithm, to be consistent with the users' guide (Hogg et al. 2003a).
}

After some algebraic manipulation, we can solve for $U$ in terms of the known layer 1 velocities:

$$
U=\frac{1}{\sqrt{2}|a+b|} \sqrt{-1+\sqrt{1+4(a+b)^{2}\left|{ }^{a} \mathbf{u}_{1}-{ }^{o} \mathbf{u}_{1}\right|^{2}}} .
$$

The velocity difference components can be expressed in terms of $U, a, b$, and the known velocities as

$$
{ }^{a} u_{m}-{ }^{o} u_{m}=\frac{{ }^{a} u_{1}-{ }^{o} u_{1}-(a+b) U\left({ }^{a} v_{1}-{ }^{o} v_{1}\right)}{1+(a+b)^{2} U^{2}} \text { and }
$$

$$
{ }^{a} v_{m}-{ }^{o} v_{m}=\frac{{ }^{a} v_{1}-{ }^{o} v_{1}+(a+b) U\left({ }^{a} u_{1}-{ }^{o} u_{1}\right)}{1+(a+b)^{2} U^{2}} .
$$

These expressions can be substituted back into Eq. (A9) to give the atmospheric wind stress. The standard scheme can be recovered by setting ${ }^{o} u_{1}={ }^{o} v_{1}=0$ to remove the oceanic QG velocity and setting $b=0$ to remove the oceanic Ekman transport. As in previous versions of Q-GCM, oceanic wind stress is computed from the atmospheric stress, using the density ratio ${ }^{o} \tau=$ ${ }^{a} \rho^{a} \boldsymbol{\tau} /^{o} \rho$. The ocean Ekman pumping velocity $w_{\mathrm{ek}}$, which is the forcing term in the QG equation for the top layer of the ocean, is then computed from the wind stress curl.

\section{REFERENCES}

Baker, D. J., 1982: A note on Sverdrup balance in the Southern Ocean. J. Mar. Res., 40, 21-26.

Böning, C. W., A. Dispert, M. Visbeck, S. R. Rintoul, and F. U. Schwarzkopf, 2008: The response of the Antarctic Circumpolar Current to recent climate change. Nat. Geosci., 1, 864 869.

Bryan, K., and M. D. Cox, 1972: The circulation of the World Ocean: A numerical study. Part I: A homogeneous model. J. Phys. Oceanogr., 2, 319-335.

Chelton, D. B., M. G. Schlax, M. H. Freilich, and R. F. Milliff, 2004: Satellite measurements reveal persistent small-scale features in ocean winds. Science, 303, 978-983.

Cornillon, P., and K. A. Park, 2001: Warm core ring velocities inferred from NSCAT. Geophys. Res. Lett., 28, 575-578.

Dawe, J. T., and L. Thompson, 2006: Effect of ocean surface currents on wind stress, heat flux, and wind power input to the ocean. Geophys. Res. Lett., 33, L09604, doi:10.1029/2006GL025784.

Dewar, W. K., and G. R. Flierl, 1987: Some effects of the wind on rings. J. Phys. Oceanogr., 17, 1653-1667.

Duhaut, T. H. A., and D. N. Straub, 2006: Wind stress dependence on ocean surface velocity: Implications for mechanical energy input to ocean circulation. J. Phys. Oceanogr., 36, 202-211.

Fyfe, J. C., and O. A. Saenko, 2005: Human-induced change in the Antarctic Circumpolar Current. J. Climate, 18, 3068-3073.

Gent, P. R., J. Willebrand, T. J. McDougall, and J. C. McWilliams, 1995: Parameterizing eddy-induced tracer transports in ocean circulation models. J. Phys. Oceanogr., 25, 463-474. 
- W. G. Large, and F. O. Bryan, 2001: What sets the mean transport through Drake Passage? J. Geophys. Res., 106 (C2), 2693-2712.

Gill, A. E., 1968: A linear model of the Antarctic circumpolar current. J. Fluid Mech., 32, 465-488.

— , and K. Bryan, 1971: Effects of geometry on the circulation of a three-dimensional southern hemisphere ocean model. DeepSea Res., 18, 685-721.

Gille, S. T., 2008: Decadal-scale temperature trends in the Southern Hemisphere Ocean. J. Climate, 21, 4749-4765.

Hallberg, R., and A. Gnanadesikan, 2001: An exploration of the role of transient eddies in determining the transport of a zonally reentrant current. J. Phys. Oceanogr., 31, 3312-3330.

- and - 2006: The role of eddies in determining the structure and response of the wind-driven Southern Hemisphere overturning: Results from the Modeling Eddies in the Southern Ocean (MESO) project. J. Phys. Oceanogr., 36, 22322252.

Hidaka, K., and M. Tsuchiya, 1953: On the Antarctic Circumpolar Current. J. Mar. Res., 12, 214-222.

Hogg, A. M., and J. R. Blundell, 2006: Interdecadal variability of the Southern Ocean. J. Phys. Oceanogr., 36, 1626-1645.

$\longrightarrow,-$, W. K. Dewar, and P. D. Killworth, 2003a: Formulation and users' guide for Q-GCM (version 1.0). Southampton Oceanography Centre, Internal Document, 40 pp. [Available online at http://www.noc.soton.ac.uk/JRD/PROC/Q-GCM/.]

- W. K. Dewar, P. D. Killworth, and J. R. Blundell, 2003b: A Quasi-Geostrophic Coupled Model (Q-GCM). Mon. Wea. Rev., 131, 2261-2278.

,-- P. S. Berloff, S. Kravtsov, and D. K. Hutchinson, 2009: The effects of mesoscale ocean-atmosphere coupling on the large-scale ocean circulation. J. Climate, 22, 4066-4082.

Houry, S., E. Dombrowsky, P. D. Mey, and J.-F. Minster, 1987: Brunt-Väisälä frequency and Rossby radii in the South Atlantic. J. Phys. Oceanogr., 17, 1619-1626.

Hughes, C. W., and C. Wilson, 2008: Wind work on the geostrophic ocean circulation: An observational study of the effect of small scales in the wind stress. J. Geophys. Res., 113, C02016, doi:10.1029/2007JC004371.

Hutchinson, D. K., 2008: Wind stress parameterisation in the Southern Ocean. Honours thesis, Research School of Earth Sciences, Australian National University, 66 pp. [Available online at http://dspace.anu.edu.au:8080/handle/1885/47691.]

Johnson, G. C., and H. L. Bryden, 1989: On the size of the Antarctic Circumpolar Current. Deep-Sea Res., 36, 39-53.

Josey, S. A., E. C. Kent, and P. K. Taylor, 2002: Wind stress forcing of the ocean in the SOC climatology: Comparisons with the NCEP-NCAR, ECMWF, UWM/COADS, and Hellerman and Rosenstein datasets. J. Phys. Oceanogr., 32, 1993-2019.
Kelly, K. A., S. Dickinson, M. J. McPhaden, and G. C. Johnson, 2001: Ocean currents evident in satellite wind data. Geophys. Res. Lett., 28, 2469-2472.

Meredith, M. P., and A. M. Hogg, 2006: Circumpolar response of Southern Ocean eddy activity to a change in the Southern Annular Mode. Geophys. Res. Lett., 33, L16608, doi:10.1029/ 2006GL026499.

Munk, W., and E. Palmén, 1951: Note on the dynamics of the Antarctic Circumpolar Current. Tellus, 3, 53-55.

— and wind mixing. Deep-Sea Res., 45, 1977-2010.

Nadeau, L.-P., and D. N. Straub, 2009: Basin and channel contributions to a model Antarctic Circumpolar Current. J. Phys. Oceanogr., 39, 986-1002.

Nonaka, M., and S. P. Xie, 2003: Covariations of sea surface temperature and wind over the Kuroshio and its extension: Evidence for ocean-to-atmosphere feedback. J. Climate, 16, 1404-1413.

O'Neill, L. W., D. B. Chelton, and S. K. Esbensen, 2003: Observations of SST-induced perturbations of the wind stress field over the Southern Ocean on seasonal timescales. J. Climate, 16, 2340-2354.

Pacanowski, R. C., 1987: Effect of equatorial currents on surface stress. J. Phys. Oceanogr., 17, 833-838.

Park, K. A., P. Cornillon, and D. L. Codiga, 2006: Modification of surface winds near ocean fronts: Effects of Gulf Stream rings on scatterometer (QuikSCAT, NSCAT) wind observations. J. Geophys. Res., 111, C03021, doi:10.1029/2005JC003016.

Pedlosky, J., 1987: Geophysical Fluid Dynamics. 2nd ed. SpringerVerlag, $710 \mathrm{pp}$.

Smith, W. H. F., and D. T. Sandwell, 1997: Global sea floor topography from satellite altimetry and ship depth soundings. Science, 277, 1956-1962.

Stern, M. E., 1975: Ocean Circulation Physics. Academic Press, $246 \mathrm{pp}$.

Straub, D. N., 1993: On the transport and angular momentum balance of channel models of the Antarctic Circumpolar Current. J. Phys. Oceanogr., 23, 776-782.

Tansley, C. E., and D. P. Marshall, 2001: On the dynamics of wind-driven circumpolar currents. J. Phys. Oceanogr., 31, 3258-3273.

Wunsch, C., 1998: The work done by the wind on the oceanic general circulation. J. Phys. Oceanogr., 28, 2332-2340.

Xu, Y., and R. B. Scott, 2008: Subtleties in forcing eddy-resolving ocean models with satellite wind data. Ocean Modell., 20, 240251.

Zhai, X., and R. J. Greatbatch, 2007: Wind work in a model of the northwest Atlantic Ocean. Geophys. Res. Lett., 34, L04606, doi:10.1029/2006GL028907. 